\title{
ESTIMATES FOR CAPACITIES AND TRACES OF POTENTIALS
}

\author{
V.G. MAZ'JA \\ Institute of Mathematics and Mechanics \\ Leningrad University \\ Leningrad, USSR \\ and \\ S.P. PREOBRAZENSKII \\ Department of Mathematics \\ Leningrad Polytechnical Institute \\ Leningrad, USSR \\ (Received June 4, 1981)
}

ABSTRACT. It is shown that "isoperimetric" inequalities, relating measures and capacities, hold for all sets in $\mathbb{R}^{\mathrm{n}}$ if they are valid for all balls. As a corollary, the necessary and sufficient conditions for the continuity of some imbeddings of M. Riesz and Bessel potential spaces are obtained. The introduction contains a survey of known results on inequalities of Sobolev type.

KEY WORDS AND PHRASES. Sobolev spaces, Bessel potential spaces, imbedding theorems, capacities, isoperimetric inequalities.

1981 MATHEMATICS SUBJECT CLASSIFICATION CODES. 31C15, 26010,28 A12.

\section{INTRODUCTION.}

(Notation is reviewed in Section 2.1, capacity and related concepts in 2.2).

In accordance with the Sobolev [1] and $\mathrm{Il}$ 'in [2] theorems for each $\mathrm{n}$ and $\mathrm{p}$, there is $a>0$ so that for all $s$, any function $u \in C_{0}^{\infty}\left(\mathbb{R}^{n}\right)$ satisfies

$$
\left.|| \mathrm{u}\right|_{\mathbb{I R}^{s}} ; \mathrm{L}^{\mathrm{q}}\left(\mathbb{R}^{\mathrm{s}}\right)\left\|\leq \mathrm{a}|| \nabla \mathrm{u} ; \mathrm{L}^{\mathrm{p}}\left(\mathbb{R}^{\mathrm{n}}\right)\right\| \text {, }
$$

where $\mathrm{n} \geq \mathrm{s}>\mathrm{n}-\mathrm{p}>0, \mathrm{p}>1, \mathrm{q}=\mathrm{ps} /(\mathrm{n}-\mathrm{p})$. This result became the starting point for many generalizations. Consider, for example, the inequality

$$
|| \mathrm{u} ; \mathrm{L}^{\mathrm{q}}\left(\mathbb{R}^{\mathrm{n}} ; \mu\right)|| \leq \mathrm{A}|| \nabla \mathrm{u} ; \mathrm{L}^{\mathrm{p}}\left(\mathbb{R}^{\mathrm{n}}\right)||
$$

where $\mathrm{u} \in \mathrm{C}_{0}^{\infty}\left(\mathbb{R}^{\mathrm{n}}\right)$; and $\mathrm{L}^{\mathrm{q}}\left(\mathbb{R}^{\mathrm{n}} ; \mu\right)$ refers to summability with respect to a measure $\mu$. 
According to a theorem by one of the authors [3] (see also [4], [5]), (1.1) follows from the "isoperimetric" inequality

$$
(\mu(E))^{\mathrm{p} / \mathrm{q}} \leq \mathrm{p}^{-\mathrm{p}}(\mathrm{p}-1)^{\mathrm{p}-1} \mathrm{~A}^{\mathrm{p}} \operatorname{cap}\left(\mathrm{E} ; \mathrm{w}_{\mathrm{p}}{ }^{1}\right)
$$

with $q \geq p$ and $E$ being any Borel set in $\mathbb{I R}^{n}$.

On the other hand, if (1.1) holds, then for any $E$

$$
(\mu(E))^{p / q} \leq A^{p} \operatorname{cap}\left(E ; w_{p}^{1}\right) \text {. }
$$

By ${ }_{p}^{1}$, we denote the completion of $C_{0}^{\infty}\left(\mathbb{R}^{n}\right)$ with the norm ||$\nabla u ; L^{p}\left(\mathbb{R}^{n}\right) \|$ and, by $\operatorname{cap}(E ; S)$, the capacity generated by the norm in the space $S$, i.e., $\operatorname{cap}(\mathrm{E} ; \mathrm{S})=\inf \left\{|| \mathrm{u} ; \mathrm{S} \|^{\mathrm{p}}: \mathrm{u} \in \mathrm{C}_{0}^{\infty} ; \mathrm{u} \geq 1\right.$ on $\left.\mathrm{E}\right\}$.

Later on that result was extended to other function spaces (see [5]-[8]). The compact statement of these generalizations runs as follows. Let $S$ be one of the spaces $\mathrm{H}_{\mathrm{p}}^{l}, \mathrm{~h}_{\mathrm{p}}^{\ell}, \mathrm{w}_{\mathrm{p}}^{\ell}, \mathrm{w}_{\mathrm{p}}^{\ell}, \mathrm{B}_{\mathrm{p}}^{\ell}, \mathrm{b}_{\mathrm{p}}^{\ell}$ (see Section 2). Then the best constant in

$$
|| \mathrm{u} ; \mathrm{L}^{\mathrm{q}}(\mu)|| \leq \mathrm{A}|| \mathrm{u} ; \mathrm{S} \|, \mathrm{u} \in \mathrm{C}_{0}^{\infty}, \mathrm{q} \geq \mathrm{p},
$$

is equivalent to the best constant in the "isoperimetric" inequality

$$
(\mu(E))^{p / q} \leq B \operatorname{cap}(E ; S) .
$$

The estimate $A \geq B$ follows immediately from the definition of capacity. The inverse is a deeper fact, its proof being based on the inequality

$$
\int_{0}^{\infty} \operatorname{cap}\left(Q_{t} ; S\right) t^{P-1} d t \leq C|| u ; S \|^{p},
$$

where $u \in S, C$ is a constant independent of $u$ and $Q_{t}=\{x:|u(x)| \geq t\}$. The validity of inequalities of the type (1.4) was discovered in Maz'ja [5]. The inequality (1.4) (and even a stronger one with capacity of the condenser $Q_{t} \backslash Q_{2 t}$ instead of $\operatorname{cap}\left(Q_{t}, S\right)$ ) was obtained in [5] for ${ }_{\mathrm{p}}{ }_{\mathrm{p}}^{\ell}$ with $\ell=1,2$. In the case $\ell=2$, the "smooth truncation" of the potential near its leyel surfaces was used in the proof. Joining this device with Hedberg inequality [9], D.R. Adams [6] proved (1.4) for Riesz potential space $h_{p} l$ with any integer $l$. The same tools, together with the Lizorkin-Uspenskii trace theorem for weighted Sobolev spaces (see [10],[11]), enabled Maz'ja to prove $(1.4)$ for $S^{\prime}=W_{p}^{\ell}$ with $\mathrm{p}>1$, $\ell>0$. As a consequence, (1.4) was obtained for the Bessel potential space $\mathrm{H}_{\mathrm{p}}^{\ell}$ with any fractiona1 $\ell$, but only with $\mathrm{p} \geq 2$.

The last restriction was removed by Dahlberg [8], whose proof also rests on "smooth truncation" and uses some subtle estimates of potentials with positive density. 
Recently, Hansson [12] gave a new proof of (1.4) for potential spaces avoiding "smooth truncation". Hansson's proof is simpler and embraces a wide class of potentials with general kernels. In Section 4 we show an even shorter proof of (1.4) based on the same idea as in [12]. This proof is taken from the paper of Maz'ja [34].

One might ask if there exists a necessary and sufficient condition for (1.4) formulated without capacity and arbitrary set E. From D.R. Adams [13] (see also [14]), it follows that the answer is positive for $S=h_{p}^{2}$, $\mathrm{p} \ell<\mathrm{n}, \mathrm{q}>\mathrm{p}>1$. His condition is

$$
\mu(B(x ; \rho)) \leq C \rho^{s}, s=q(n / p-l),
$$

where $B(x ; \rho)$ is any ball with arbitrary center $x \in \mathbb{R}^{n}$ and radius $\rho$. In other words, it is sufficient to check (1.3) for balls only. According to [14], the condition (1.5) yields

$$
\mu\left(\left\{x: I_{\ell}|f(x)|>t\right\}\right) \leq a C t^{-q}|| f||_{p}^{q}
$$

where $I_{\ell}$ is the Riesz potential. This and Marcinkiewicz's interpolation theorem give the continuity of the operator $I_{\ell}: L^{p}\left(R^{n}\right) \rightarrow L^{q}\left(\mathbb{R}^{n} ; \mu\right)$, or the estimate (1.2) with $\mathrm{S}=\mathrm{h}_{\mathrm{p}}^{\ell}, \ell>0, \mathrm{q}>\mathrm{p}>1$, which is the same.

Thus, the estimate (1.5) (with $q>p$ ) for any ball implies (1.3) for any set. It is an attempt to get a direct proof of the last implication that gave rise to the present paper. Such a proof was found and its analysis led the authors to theorems of the following type.

For any ball $B(x ; r)$, let

$$
\mu(B(x ; r)) \leq \phi\left(\operatorname{cap}\left(B(r) ; h_{p}^{\ell}\right)\right)
$$

where $B(r)=B(0 ; r)$, $\phi$ is an increasing function subjected to additional conditions, and $\mu$ is a measure in $\mathbb{R}^{n}$. Then there is a $>0$ so that for any Borel set $E \in \mathbb{R}^{n}$,

$$
\mu(E) \leq a \Phi\left(a \operatorname{cap}\left(E ; h_{p}^{\ell}\right)\right)
$$

By this and similar facts, we show in the second part of the paper that inequalities of the type (1.6) are necessary and sufficient for estimates of traces of Riesz and Bessel potentials in Orlicz spaces. In particular, we obtain a new proof of the aforementioned D.R. Adams theorem [13, 14]. Another corollary which may be of interest, claims that the inequality

$$
|| \mathrm{u} ; \mathrm{L}^{\mathrm{T}}(\mu)|| \leq \mathrm{a}|| \mathrm{u} ; \mathrm{H}_{\mathrm{P}} \mathrm{x}^{0}||
$$


with $q>p>1$ and $\ell_{p}=n$ holds if and only if, for any ball $\mathrm{B}(\mathrm{x} ; \mathrm{r})$ with $\mathrm{r} \in(0,1 / 2)$,

$$
\mu(B(x ; r)) \leq a|\log r|^{-q / p} .
$$

We state now some other results relating the conditions for (1.2).

If $\mathrm{S}=\mathrm{H}_{\mathrm{p}}^{\ell}$ and $\mathrm{p} \ell<\mathrm{n}$, then (1.2) holds simultaneously with $(1.5)$ where $0<\mathrm{r}<1$ (see Section 4).

In a simpler case, $\mathrm{p} l>\mathrm{n}$, the necessary and sufficient condition for (1.2) with $\mathrm{S}=\mathrm{H}_{\mathrm{p}}^{l}$ is

$$
\sup \left\{\mu(B(x ; 1)): \quad x \in \mathbf{R}^{\mathbf{n}_{1}}<\infty\right.
$$

(see Section 4, Note 4.1).

According to a remark in D.R. Adams [9] (see Note 4.1 below), the condition (1.5) is not sufficient for $(1.2)$, when $q=p$, so one has to deal with the less explicit condition (1.3) in this case, probably the most important for applications.

For $\mathrm{p}>\mathrm{q}>0$, the necessary and sufficient condition was obtained in the paper of V.G. Maz'ja [34]. Its formulation runs as follows.

Let $\left\{g_{j}\right\}_{j=-\infty}^{+\infty}$ be any sequence of open sets, such that $\bar{g}_{j+1} \subset g_{j}$. Let $\mu_{j}=\mu\left(g_{j}\right)$, $\gamma_{j}=\operatorname{cap}\left(g_{j}, S\right)$, where $s=h_{p}^{l}$ or $S=H_{p}^{l}, p>1$. The inequality (1.2) holds if and only if

$$
\sum_{j=-\infty}^{+\infty}\left(\frac{\left(\mu_{j}-\mu_{j+1}\right)^{1 / q}}{\gamma_{j}^{1 / p}}\right)^{\frac{p q}{p-q}} \leq \text { const. }
$$

This provides the sufficient condition

$$
\int_{0}^{\infty}\left(\frac{t}{\phi(t)}\right)^{\frac{q}{p-q}} d t<\infty .
$$

where $\phi(t)=\inf \{\operatorname{cap}(E ; S): \mu(E) \geq t\}$.

In case $\mathrm{p} l>\mathrm{n}, \mathrm{p}>\mathrm{q}$, the necessary and sufficient condition for (1.2) can be written in the simpler form

$$
\sum_{i}\left(\mu\left(Q_{i}\right)\right)^{\frac{p}{p-q}}<\infty,
$$

where $\left\{Q_{\mathbf{i}}\right\}$ is a sequence of closed cubes with side 1 , forming the coordinate grid in $\mathrm{IR}^{\mathrm{n}}$.

We note also that, in case $q=1$ and $p>1$, the inequality $(1.2)$ with $S=h_{p}^{l}$ or 
$S=H_{p}^{\ell}$ is equivalent to inclusion $I_{\ell} \mu \in L^{p^{\prime}}$ or $J_{\ell} \mu \in L^{p^{\prime}}$ respectively [5] (here $I_{\ell}$ and $\mathrm{J}_{\ell}$ are the Riesz and Bessel potentials).

We now dwell on the case $p=1$. For $S=w_{1}^{2}$, it is shown in [15] that (1.2) holds simultaneously with $(1.5)$, where $p=1, q \geq 1$. One has to add the condition $\rho \in(0,1)$ in $(1.5)$, if $s=w_{p}^{l}$. For the case $p=1$, see also [35]-[39], [7].

Using the fact that $\mathrm{b}_{\mathrm{p}}^{\ell}$ and $\mathrm{B}_{\mathrm{p}}^{\ell}, \mathrm{p}>1$, are the trace spaces of the corresponding potential spaces, we obtain theorems on $\mathrm{b}_{\mathrm{p}}^{\ell}$ and $\mathrm{B}_{\mathrm{p}}^{\ell}$ from the theorems on $\mathrm{h}_{\mathrm{p}}^{\ell}$ and $\mathrm{H}_{\mathrm{p}}^{\ell}$

We note also that our technique enables one to obtain similar results for potentials with general kernels $k(|x-y|)$ of some class. The papers [16] and [12] provide a basis for such generalizations.

Concluding the introduction, we remark that integral inequalities for functions in subdomains of $\mathbf{R}^{\mathrm{n}}$ are studied in [39] and [40] where other references can be found. 2. NOTATION AND PRELIMINARIES.

\subsection{BASIC NOTATION:}

Let $\mathbb{R}^{\mathrm{n}}$ be $\mathrm{n}$-dimensional Euclidean space, $\mathrm{B}(\mathrm{x} ; \mathrm{r})=\left\{\mathrm{y} \in \mathbb{R}^{\mathrm{n}}:|\mathrm{y}-\mathrm{x}|<\mathrm{r}\right\}$, $B(r)=B(0 ; r)$. By $\mu, \nu$, we denote measures in $\mathbb{R}^{n}$, i.e., non-negative, completely additive set functions, defined on a Borel $\sigma$-algebra $\mathscr{D}$ of the space $\mathbb{R}^{\mathrm{n}}$.

Let $L^{q}(\mu)$ be the set of measurable functions defined on the measure space $\left(\mathbb{R}^{\mathrm{n}}, \mathscr{D}, \mu\right)$ such that $|\mathrm{f}|^{\mathrm{q}}$ is integrable, $0<\mathrm{q}<\infty$. We put

$$
\left\|\mathrm{f} ; \mathrm{L}^{\mathrm{q}}(\mu)\right\|=\left(\int|\mathrm{f}|^{\mathrm{q}} \mathrm{d} \mu\right)^{1 / \mathrm{q}} \text {. }
$$

Integration is over the whole space $\mathbb{R}^{\mathrm{n}}$ if nothing else is indicated, the same relates the notation of functional spaces. If $\mu$ is $n$-dimensional Lebesgue measure we shall use the notation $\mathrm{L}^{\mathrm{q}}$ instead of $\mathrm{L}^{\mathrm{q}}(\mu)$ and write $\|\mathrm{f}\|_{\mathrm{q}}$ intead of $\left\|\mathrm{f} ; \mathrm{L}^{\mathrm{q}}(\mu)\right\|$. In other cases, we shall denote the norm in the space $s$ by $\|f ; s\|$.

As usual, $C_{0}^{\infty}$ is the space of infinitely differentiable functions in $\mathbb{R}^{\mathrm{n}}$ with compact support. Everywhere below $a, b, c$ are positive constants, depending only on $n, p, l$ and so forth. Two values $A$ and $B$ will be called equivalent $(A \sim B)$ if there exist constants $a$ and $b$ such that $a A \leq B \leq b A$.

Let $1<\mathrm{p}<\infty$. We introduce spaces $\mathrm{h}_{\mathrm{p}}^{\ell}$ and $\mathrm{H}_{\mathrm{p}}^{\ell}$ as completions of $\mathrm{C}_{0}$ with norms $\left\|\mathrm{u} ; \mathrm{h}_{\mathrm{p}}^{\ell}\right\|=\left\|(-\Delta)^{\ell / 2} \mathrm{u}\right\|_{\mathrm{p}}$ and $\left\|\mathrm{u} ; \mathrm{H}_{\mathrm{p}}^{\ell}\right\|=\left\|(-\Delta+1)^{\ell / 2} \mathrm{u}\right\|_{\mathrm{p}}$, where 


$$
(-\Delta)^{l / 2}=(2 \pi)^{l} F^{-1}|\xi|^{l} F ;(-\Delta+1)^{l / 2}=F^{-1}\left(1+4 \pi^{2}|\xi|^{l / 2} F\right.
$$

and $\mathrm{F}$ is the Fourier transform in $\mathbb{R}^{\mathrm{n}}$ (see [17]).

As is well known [17], any element of the space $h_{p}^{l}$ (the space $H_{p}^{l}$ ) can be considered as a Riesz potential $I_{\ell} f$ (Bessel potential $J_{\ell} f$ ) with the density from $L^{p}$ and

$$
\|\mathrm{f}\|_{\mathrm{p}}=\mathrm{b}\left\|\mathrm{I}_{\ell} \mathrm{f} ; \mathrm{h}_{\mathrm{p}}^{\ell}\right\| ;\|\mathrm{f}\|_{\mathrm{p}}=\left\|\mathrm{J} \ell^{\mathrm{f}} ; \mathrm{H}_{\mathrm{p}}^{\ell}\right\| \text {. }
$$

That is why $h_{p}^{\ell}$ and $H_{p}^{l}$ are called the spaces of Riesz and Bessel potentials.

For $\mathrm{p} \geq 1$ and integer $\ell>0$ we denote by $w_{p}^{\ell}$ and $w_{p}^{l}$ the completions of $c_{0}^{\infty}$ with respect to norms $\|\left.\nabla_{\ell} u\right|_{p}$ and $\left\|\nabla_{\ell} u\right\|_{p}+\|u\|_{p}$ where $\nabla_{\ell}=\left\{\partial^{\alpha} / \partial x_{1}{ }_{1}, \ldots, \partial x_{n}{ }^{n}\right\},|\alpha|=\ell$. The spaces $h_{p}^{l}$ and $w_{p}^{\ell}$ as well as $H_{p}^{l}$ and $w_{p}^{l}$ coincide for $p>1$.

If $p \geq 1$ and $\ell$ is not an integer, then by $w_{p}^{\ell}$ we denote the completion of $r_{0}^{\infty}$ with the norm

$$
\left(\int|| \Delta_{t} u ; h_{p}^{[l]}||^{p} \cdot|t|^{-n-p\{l\}} d t\right)^{1 / p},
$$

where $\Delta_{t} u(x)=u(x+t)-u(x),[l]$ and $\{l\}$ are the integer and the fractional parts of $\ell$.

If we substitute the norm (2.1) in this definition with the norm

$$
\left\|\mathrm{u} ; \mathrm{b}_{\mathrm{p}}^{\ell}\right\|=\left(\int\left\|\Delta_{\mathrm{t}} \mathrm{u}\right\|_{\mathrm{p}}^{\mathrm{p}} \mathrm{t}^{-\mathrm{n}-\mathrm{p} \ell} \mathrm{dt}\right)^{1 / \mathrm{p}}, 0<\ell<1,
$$

then we obtain the definition of the space $b_{\mathrm{p}}^{l}$. In the case $\bar{l}=1$ the first difference in (2.2) should be replaced by the second one. For $l>1$, we set

$$
\left\|\mathrm{u} ; \mathrm{b}_{\mathrm{p}}^{\ell}\right\|=\left\|\nabla \mathrm{u} ; \mathrm{b}_{\mathrm{p}}^{\ell-1}\right\| \text {. }
$$

As is known, the norms in spaces $w_{p}^{l}$ and $b_{p}^{\ell}$ are equivalent for fractional $\ell$.

We also introduce the spaces $\mathrm{w}_{\mathrm{p}}^{\ell}$ and $\mathrm{B}_{\mathrm{p}}^{l}$ as completions of $C_{0}^{\infty}$ with norms $\left\|\mathrm{u} ; \mathrm{w}_{\mathrm{p}}^{\ell}\right\|+\|\mathrm{u}\|_{\mathrm{p}}$ and $\left\|\mathrm{u} ; \mathrm{b}_{\mathrm{p}}^{\ell}\right\|+\|\mathrm{u}\|_{\mathrm{p}}$ respectively.

We assume $\mathrm{p}>1$ everywhere below.

2.2. SOME NOTIONS OF POTENTIAL THEORY:

To each functional space $\mathrm{S}$ introduced in 2.1 , we can assign a set function called capacity. For any compact $\mathrm{e}^{\subset} \mathbb{R}^{\mathrm{n}}$, we put

$$
\operatorname{cap}(e ; s)=\inf \left\{\|\mathrm{u} ; \mathrm{s}\|^{\mathrm{P}}: \mathrm{u} \in \mathrm{C}_{0}^{\infty} ; \mathrm{u} \geq 1 \text { on } \mathrm{e}\right\} .
$$

If $\mathrm{E}$ is any subset of $\mathbb{R}^{\mathrm{n}}$, then inner and outer capacities of $\mathrm{E}$ are defined by 


$$
\begin{aligned}
& \text { cap }(E ; S)=\sup \{\operatorname{cap}(e ; S): \text { e } \subset E, \text { e is a compact set }\}, \\
& \overline{\operatorname{cap}}(E ; S)=\inf \{\operatorname{cap}(G ; S): G \supset E, G \text { is an open set }\} .
\end{aligned}
$$

We formulate now some known properties of the capacity cap $(\bullet$; $S$ ) (see, for example, [18], [19]).

1) If the set $e \subset \mathbb{R}^{n}$ is compact, then for any $\varepsilon>0$ there exists an open set $G \subset \mathbb{R}^{n}$ such that $G \supset$ e and $\operatorname{cap}(e ; S)<\operatorname{cap}\left(e^{\prime} ; S\right)+\varepsilon$ for any compact subset $e^{\prime}$ of $G$.

2) If the set $e \subset \mathbb{R}^{n}$ is compact, then $\overline{\operatorname{cap}}(e ; S)=\operatorname{cap}(e ; S)$.

3) If $E_{1} \subset E_{2} \subset \mathbb{R}^{n}$, then $\underline{\operatorname{cap}}\left(E_{1} ; S\right) \leq \operatorname{cap}\left(E_{2} ; S\right), \overline{\operatorname{cap}}\left(E_{1} ; S\right) \leq \overline{\operatorname{cap}}\left(E_{2} ; S\right)$.

4) Let $\left\{E_{k}\right\}_{k=1}^{\infty}$ be a sequence of sets in $\mathbb{R}^{n}$ such that $E=\bigcup_{k} E_{k}$. Then

$$
\overline{\operatorname{cap}}(E ; S) \leq \sum_{k=1}^{\infty} \overline{\operatorname{cap}}\left(E_{k} ; S\right) \text {. }
$$

It is known (see [18], [19]) that any analytic (in particular, any Borel) subset $\mathrm{E}$ of $\mathbb{K}^{\mathrm{n}}$ is measurable with respect to the capacity $\operatorname{cap}(\bullet ; \mathrm{S})$ (i.e. $\overline{\operatorname{cap}}(\mathrm{E} ; \mathrm{S})=\underline{\operatorname{cap}}(\mathrm{E} ; \mathrm{S})$ )

The following set function, also called capacity, is useful for different applications

$\operatorname{Cap}(\mathrm{e} ; \mathrm{S})=\inf \left\{|| \mathrm{u} ; \mathrm{S} \|^{\mathrm{p}}: \mathrm{u} \in \mathrm{C}_{0}^{\infty}, 0 \leq \mathrm{u} \leq 1\right.$ in $\mathbb{R}^{\mathrm{n}}, \mathrm{u}=1$ in a neighborhood of e\}. (Sometimes the condition $0 \leq \mathrm{u} \leq 1$ is omitted in this definition). According to [20], [21] (for integer $\ell$ ) and to [22] (for al1 $\ell>0$ ),

$$
\operatorname{Cap}\left(e ; \mathrm{H}_{\mathrm{p}}^{\ell}\right) \sim \operatorname{cap}\left(\mathrm{e} ; \mathrm{H}_{\mathrm{p}}^{\ell}\right) \text {. }
$$

The relations of the type (2.3) hold for $s=h_{p}^{\ell}, B_{p}^{\ell}, b_{p}^{l}$.

Along with capacities $\operatorname{cap}(\bullet ; S)$ and $\operatorname{Cap}(\bullet ; S)$ the following capacity $C_{k, p}(E)=\inf \left\{\|\left. f\right|_{p} ^{p}: f \in L_{+}^{p}\right.$ and $\int k(y-x) f(y) d y \geq 1$ for all $\left.x \in E\right\}$, where $k$ is a positive decreasing continuous function on $(0,+\infty)$ is introduced in [19] (the function $k$ is called a kernel).

We present now some connections between capacities.

PROPOSITION 2.1.

(i) If $\mathrm{S}=\mathrm{H}_{\mathrm{p}}^{\ell}$ or $\mathrm{S}=\mathrm{h}_{\mathrm{p}}^{\ell}$ and $\mathrm{k}$ is a Bessel or Riesz Kernel, then

$$
\operatorname{cap}(E ; S) \sim C_{k, p}(E) .
$$

(ii) If $\operatorname{diamE} \leq 1$ and $\mathrm{p} \ell<\mathrm{n}$, then

$$
\operatorname{cap}\left(E ; H_{p}^{l}\right) \sim \operatorname{cap}\left(E ; h_{p}^{l}\right)
$$


(see [23]). Relations analogous to (2.4) also hold for other pairs of spaces $B_{p}^{l}$, $b_{p}^{l}$ and $\mathrm{w}_{\mathrm{p}}^{\ell}, \mathrm{w}_{\mathrm{p}}^{\ell}$.

(iii) If $2 \leq \mathrm{p}<\infty$, then

$$
\operatorname{cap}\left(\mathrm{E} ; \mathrm{H}_{\mathrm{p}}^{\ell}\right) \sim \operatorname{cap}\left(\mathrm{E} ; \mathrm{B}_{\mathrm{p}}^{l}\right)
$$

(see [24]). Moreover, for $2-\ell / \mathrm{n}<\mathrm{p}<2$ the equalities $\operatorname{cap}\left(\mathrm{E} ; \mathrm{H}_{\mathrm{p}}^{\ell}\right)=0$ and $\operatorname{cap}\left(\mathrm{E} ; \mathrm{B}_{\mathrm{p}}^{\ell}\right)=0$ hold simultaneously [25]. For any $p \in(1,+\infty), l>0$,

$$
\operatorname{cap}\left(\mathrm{E} ; \mathrm{H}_{\mathrm{p}}^{\ell}\right) \leq \mathrm{c} \operatorname{cap}\left(\mathrm{E} ; \mathrm{B}_{\mathrm{p}}^{\ell}\right) \text {, }
$$

where $\mathrm{c}$ is a constant, depending on $1 \mathrm{y}$ on $\mathrm{n}, \mathrm{p}, \mathrm{l}$ ([24], [25]).

$$
\begin{aligned}
& \text { (iv) If } \mathrm{E} \subset \mathbb{R}^{\mathrm{n}}, \ell>0,1<\mathrm{p}<\infty \text {, then } \\
& \operatorname{cap}\left(\mathrm{E} ; \mathrm{B}_{\mathrm{p}}^{\ell}\left(\mathbb{R}^{\mathrm{n}}\right)\right) \sim \operatorname{cap}\left(\mathrm{E}: \mathrm{H}_{\mathrm{p}}^{\ell+1 / \mathrm{p}}\left(\mathbb{R}^{\mathrm{n}+1}\right)\right) \sim \operatorname{cap}\left(\mathrm{E} ; \mathrm{B}_{\mathrm{p}}^{\ell+1 / \mathrm{p}}\left(\mathbb{R}^{\mathrm{n}+1}\right)\right)
\end{aligned}
$$

(see [24]).

By $\mathrm{U}_{\ell, \mathrm{p}}^{\mu}$ and $\mathrm{v}_{\ell, \mathrm{p}}^{\mu}$ we denote the nonlinear Riesz and Bessel potentials $((\ell, \mathrm{p})$-potentials) of a measure $\mu$ i.e.

$$
\mathrm{U}_{\ell, \mathrm{p}}^{\mu}=\mathrm{I}_{\ell}\left(\mathrm{I}_{\ell} \mu\right)^{\mathrm{P}^{\prime}-1}, \quad \mathrm{v}_{\ell, \mathrm{p}}^{\mu}=\mathrm{J}_{\ell}\left(\mathrm{J}_{\ell}^{\mu)^{\mathrm{P}^{\prime}-1}} .\right.
$$

The following rough maximum principle holds for the potentials $U_{\ell, p}^{\mu}$ and $v_{\ell, p}^{\mu}$.

PROPOSITION 2.2. Let $\mathrm{P}^{\mu}$ be one of the potentials $\mathrm{U}_{\ell, \mathrm{p}}^{\mu}$ or $\mathrm{v}_{\ell, \mathrm{p}}^{\mu}$. Then there exists a constant $M$, depending only on $n$ such that

$$
\mathrm{P}^{\mu}(\mathrm{x}) \leq \mathrm{M} \sup \left\{\mathrm{P}^{\mu}(\mathrm{x}): \quad \mathrm{x} \in \operatorname{supp} \mu\right\} .
$$

This statement is proved in [18], [23].

The following known assertion contains the basic properties of the so-called $(\ell, \mathrm{p})$-capacitary measure.

PROPOSITION 2.3. (see [18], [19]) Let $E$ be a subset of $\mathbb{R}^{n}$. If $\overline{\operatorname{cap}}\left(E ; h_{p}^{l}\right)<+\infty$, then there exists a unique measure $\mu_{E}$ with the properties:

$$
\begin{aligned}
& \text { 1) }\left\|I_{\ell} \mu_{E}\right\|_{p^{\prime}}^{p^{\prime}}=\overline{\overline{c a p}}\left(E ; h_{p}^{2}\right), \\
& \text { 2) } U_{\ell, p}^{\mu_{E}}(x) \geq 1 \text { for }(\ell, p)-q . e \text { on } E \text {. }
\end{aligned}
$$

(A property which holds except on a set $E$ with $\operatorname{cap}\left(E ; h_{p}^{\ell}\right)=0$ is said to hold $(\ell, p)-$ q.e. on E).

$$
\text { 3) supp } \mu_{E} \subset \bar{E} \text {, }
$$




$$
\begin{aligned}
& \text { 4) } \mu_{E}(\bar{E})=\overline{\operatorname{cap}}\left(E ; h_{p}^{\ell}\right), \\
& \text { 5) } \bigcup_{\ell, p}^{\mu_{E}}(x) \leq 1 \text { for a11 } x \in \operatorname{supp} \mu_{E} \text {. }
\end{aligned}
$$

The measure $\mu_{E}$ is called the capacitary measure of the set $\mathrm{E}$.

We will also use the notation $U_{\ell, p}^{\mu}$ for the capacitary potential of $\mathrm{E}$.

This proposition still holds after the replacement of $h_{p}^{\ell}$ by $H_{p}^{l}$ and $U_{\ell, p}^{\mu}$ by $v_{\ell, p}^{\mu}$. We note also that, according to [18], the capacities cap(K;S) with $S=h_{p}^{l}$ or $H_{p}^{\ell}$ can be defined as $\operatorname{cap}(\mathrm{K} ; \mathrm{S})=\sup \left\{\mu(\mathrm{K}): \operatorname{supp} \mu \subset \mathrm{K}\right.$ and $\mathrm{P}^{\mu}(\mathrm{x}) \leq 1$ on $\left.\operatorname{supp} \mu\right\}$.

The following relations are also of use (see [19]). If $\mathrm{p} \ell<\mathrm{n}$ and $0<\rho \leq 1$, then

$$
\operatorname{cap}\left(B(\rho) ; H_{p}^{\ell}\right) \sim \rho^{n-p l} .
$$

If $\mathrm{pl}<\mathrm{n}$ and $0<\rho<\infty$, then

$$
\operatorname{cap}\left(B(\rho) ; h_{p}^{l}\right)=c \rho^{n-p l}
$$

If $\mathrm{pl}=\mathrm{n}$ and $0<\rho \leq 1$, then

$$
\operatorname{cap}\left(B(\rho) ; H_{\mathrm{P}}^{l}\right) \sim(\log 2 / \rho)^{1-p}
$$

If $\mathrm{pl}>\mathrm{n}$, then $\operatorname{cap}\left(\{\mathrm{x}\} ; \mathrm{H}_{\mathrm{p}}^{\ell}\right)>0$ (so only the empty set has zero capacity).

For arbitrary set $E \subset \mathbb{R}^{n}$ and arbitrary non-decreasing function $\phi$ on $[0,+\infty)$ we define the Hausdorff $\phi$ measure:

$$
H(E ; \phi)=\lim _{\varepsilon \rightarrow 0} \inf _{\left\{B_{i}\right\}} \sum_{i} \phi\left(r_{i}\right),
$$

where $\left\{B_{i}\right\}$ is any covering of $E$ by open balls $B_{i}$ with radii $r_{i}<\varepsilon$. If $\phi(t)=t^{S}$, then $s$ is called the dimension of the Hausdorff measure. By the s-dimensional Hausdorff measure of $\mathrm{E}$, we call the value $H_{S}(E)=v_{S} H\left(E ; t^{s}\right)$, $v_{s}$ being the $s$-dimensional Lebesgue measure of the $s$-dimensional unit ball. For $s=n$ the Hausdorff measure $H_{s}$ coincides with $n$-dimensional Lebesgue measure $\mathrm{m}_{\mathrm{n}}$.

The next two propositions contain different, but in a certain sense exact necessacy and sufficient conditions for positivity of capacity. These conditions are formulated in terms of the Hausdorff measure.

PROPOSITION 2.4. ([18], [26]). Let $\mathrm{S}=\mathrm{h}_{\mathrm{p}}^{\ell}(1<\mathrm{p}<\mathrm{n} / \ell)$ or $\mathrm{S}=\mathrm{H}_{\mathrm{p}}^{\ell}(1<\mathrm{p} \leq \mathrm{n} / \mathrm{l})$ and $h$ be a non-negative non-decreasing function on $[0,+\infty)$ such that $h(0)=0$ and

$$
\int_{0}\left(\frac{h(t)}{t^{n-p l}}\right)^{p^{\prime}-1} \frac{d t}{t}<+\infty .
$$


Then $\operatorname{cap}(E ; S)>0$ for any Borel set $E \subset \mathbb{R}^{\mathbf{n}}$ with a positive Hausdorff h-measure. PROPOSITION 2.5. ([26], [19]). Let $E$ be a Borel set in $\mathbb{R}^{n}$.

1) If $\mathrm{n}>\mathrm{p} \ell$ and $\mathrm{H}_{\mathrm{n}-\mathrm{p} \ell}(E)<\infty$, then cap $(E ; S)=0$, where $\mathrm{S}=\mathrm{h}_{\mathrm{p}}^{\ell}$ or $\mathrm{S}=\mathrm{H}_{\mathrm{p}}^{\ell}$.

2) If $n=p \ell$ and $H(E ; h)<\infty$ with $h(r)=|\log r|^{1-p}$, then $\operatorname{cap}\left(E ; H_{p}^{\ell}\right)=0$.

\subsection{ORLICZ SPACES.}

Let function $M$ be defined on $\mathbb{R}^{1}$ by the formula

$$
M(u)=\int_{0}^{|u|} p(t) d t,
$$

where $p$ is a positive function of $\mathbb{R}_{+}^{1}$ continuous from the right, non-decreasing and such that $p(0)=0, p(t) \rightarrow+\infty$ as $t \rightarrow+\infty$. Let then $q$ be right inverse to $p(t)$, i.e. $q(s)=\sup \{t: p(t) \leq s\}$. The function

$$
N(u)=\int_{0}^{|u|} q(t) d t
$$

is called complementary to $M(u)$.

We denote by $L_{M}(\mu)$ the set of measurable functions defined on $\left(\mathbb{R}^{n} ; \beta\right)$, for which $\left\|f ; L_{M}(\mu)\right\|=\sup \left\{\int f g d \mu: \int N(g) d \mu \leq 1\right\}<+\infty$. If $M(t)=|f|^{q} / q(q>1)$, then $N(r)=|f|^{q^{\prime}} / q^{\prime}$ and

$$
\left\|f ; L_{M}(\mu)\right\|=q^{1 / q^{\prime}}\left\|f ; L^{q}(\mu)\right\| \text {. }
$$

We also note (see [27]) that $I_{M}(\mu)$ - norm of the characteristic function of a set $E$ is

$$
|| X_{E} ; L_{M}(\mu) \|=\mu(E) N^{-1}(1 / \mu(E)) \text {, }
$$

where $\mathrm{N}^{-1}(\mathrm{u})$ is the inverse function to $\mathrm{N}(\mathrm{v})$.

Finally, it is worth noting that according to [27] the spaces $L_{M_{1}}(\mu)$ and $L_{M_{2}}(\mu)$ consist of the same functions if and only if there exists positive constants $K_{1}, K_{2}$ and $u_{0}$ such that for $u \geq u_{0}$

$$
M_{1}\left(k_{1} u\right) \leq M_{2}(u) \leq M_{1}\left(k_{2} u\right) .
$$

3. THE CARTAN TYPE THEOREMS FOR $(\ell, p)$-POTENTIALS AND ESTIMATES FOR $(\stackrel{0}{p}, \mathrm{p})$-CAPACITIEs.

In this section we prove the equivalence of inequalities (1.6) and (1.7). This will be obtained as a consequence of the Theorem 3.1, which provides an estimate of thickness of the set, where the $(x, p)$-potential exceeds a given value. Such estimates were obtained first for harmonic functions by Cartan [28] (see also [29]). For linear Riesz potentials, they are given in Landhoff ([30], Chap. III, Section 4). 
The same scheme is used in the nonlinear case, but its performance needs some recently obtained non-trivial estimates for $(\ell, p)$-potentials, which are obvious for linear potentials. Such estimates are collected in the following

PROPOSITION 3.1. 1. If $2-\ell / \mathrm{n}<\mathrm{p}<\mathrm{n} / \ell$, then

$$
I_{\ell, p}^{\mu}(x) \leq a \int_{0}^{\infty}\left(\frac{\mu(B(x ; \rho))}{\rho^{n-p l}}\right)^{\frac{1}{p-1}} \frac{d \rho}{\rho} \text {. }
$$

2. If $1<\mathrm{p}<2-\ell / \mathrm{n}$ and $U_{\ell, \mathrm{p}}^{\mu}(\mathrm{x}) \leq \mathrm{K}$ for all $\mathrm{x} \in \mathbb{R}^{\mathrm{n}}$, then

$$
U_{\ell, p}^{\mu}(x) \leq a K^{\gamma} \int_{0}^{\infty}\left(\frac{\mu(B(x ; \rho))}{\rho^{n-p l}}\right)^{\frac{n-\ell}{n-p l}} \frac{d \rho}{\rho},
$$

where $\gamma=((2-p) n-\ell) /(n-p l)$.

3. If $\mathrm{p}=2-\ell / \mathrm{n}$ and $\mathrm{U}_{\ell, \mathrm{p}}^{\mu}(\mathrm{x}) \leq \mathrm{K}$ for all $\mathrm{x} \in \mathbf{R}^{\mathrm{n}}$, then

$$
\mathrm{U}_{\ell, p}^{\mu}(\mathrm{x}) \leq \mathrm{b} \int_{0}^{\infty}\left[\frac{\mu(\mathrm{B}(\mathrm{x} ; \mathrm{r}))}{\mathrm{r}^{\mathrm{n}-\mathrm{p} \ell}} \log \left(\mathrm{aK}^{\mathrm{p}-1} \frac{\mathrm{r}^{\mathrm{n}-\mathrm{p} \ell}}{\mu(\mathrm{B}(\mathrm{x} ; \mathrm{r}))}\right)\right]^{\mathrm{p}^{\prime}-1} \frac{\mathrm{dr}}{\mathrm{r}} .
$$

(From the condition $U_{\ell, p}^{\mu}(x) \leq K$ for all $x \in \mathbb{R}^{n}$ it follows that $\mu(B(x ; r)) \leq$ $\mathrm{e}^{-1} a K^{\mathrm{p}-1} \mathrm{r}^{\mathrm{n}-\mathrm{pl}}$.)

4. If $\mathrm{p}=\mathrm{n} / \ell$, then

$$
v_{\ell, p}^{\mu}(x) \leq a \int_{0}^{\infty}(\mu(B(x ; r)))^{p^{\prime}-1} e^{-b r} \frac{d r}{r}
$$

The estimate (3.1) is obtained in papers [26], [18]; the estimates (3.2) and (3.3) are proved in [16]; (3.4) is found in [13].

We now turn to working out the upper estimates for $(l, p)$-potentials in the complement of some set.

LEMMA 3.1. Let $1<\mathrm{p} \leq \mathrm{n} / \ell, \mu$ be a finite measure in $\mathbb{R}^{\mathrm{n}}$, and $\mathrm{h}$ be a non-decreasing function on $[0,+\infty)$, such that $h(0)=0, h(r)=h\left(r_{0}\right)=\mu\left(\mathbb{R}^{n}\right)$ for $r>r_{0}$. In case $\mathrm{p} \in(1, \ell-\ell / \mathrm{n}]$ suppose additionally that $\mathrm{U}_{2, \mathrm{p}}^{\mu}(\mathrm{x}) \leq \mathrm{K}<+\infty$ for all $\mathrm{x} \in \mathbb{R}^{\mathrm{n}}$ and $h(r) \leq e^{-1} a K^{p-1} r^{n-p l}$, where a is a constant from the inequality (3.3).

Let $D$ be a set $\left\{x \in \mathbf{R}^{n}: P^{\mu}(x)>c W[h]\right\}$, where $P^{\mu}=U_{l, p}^{\mu}$, if $p l<n ; P^{\mu}=v_{l, p}^{\mu}$, if $\mathrm{pl}=\mathrm{n}$; and 


$$
W[h]=\left\{\begin{array}{l}
\int_{0}^{\infty}\left(\frac{n(r)}{r^{n-p l}}\right)^{p^{\prime}-1} \frac{d r}{r}, \text { if } 2-\ell / n<p<n / \ell ; \\
K^{\gamma} \int_{0}^{\infty}\left(\frac{h(r)}{r^{n-p l}}\right)^{\frac{n-l}{n-p l}} \frac{d r}{r}, \text { if } 1<p<2-\ell / n ; \\
\int_{0}^{\infty}\left(\frac{h(r)}{r^{n-p l}} \log \left(a K^{p-1} \frac{r^{n-p l}}{h(r)}\right)\right)^{p^{\prime}-1} \frac{d r}{r}, \text { if } p=2-\ell / n ; \\
\int_{0}^{\infty}(h(r))^{p^{\prime}-1} e^{-b r} \frac{d r}{r} \text { if } p=n / \ell,
\end{array}\right.
$$

where $\gamma=((2-p) n-\ell)(n-p l)^{-1}$.

Then the set $D$ can be covered by a sequence of balls with radii $r_{k} \leq r_{0}$ satisfying the inequality

$$
\sum_{K} h\left(r_{K}\right) \leq c \mu\left(\mathbb{R}^{n}\right)
$$

PROOF. Consider the case $2-\ell / n<p<n / \ell$. Let $x \in D$. Suppose that $\mu(B(x ; r)) \leq h(r)$ for all $r>0$. Then, using (3.1), we obtain

$$
\mathrm{U}_{\ell, \mathrm{p}}^{\mu}(\mathrm{x}) \leq c \int_{0}^{\infty}\left(\frac{\mu(\mathrm{B}(\mathrm{x} ; \mathrm{r}))}{\mathrm{r}^{\mathrm{n}-\mathrm{p} \ell}}\right)^{\mathrm{p}^{\prime}-1} \frac{\mathrm{dr}}{\mathrm{r}}<c \int_{0}^{\infty}\left(\frac{\mathrm{h}(\mathrm{r})}{\mathrm{r}^{\mathrm{n}-\mathrm{p} \ell}}\right)^{\mathrm{p}^{\prime}-1} \frac{\mathrm{dr}}{\mathrm{r}},
$$

which contradicts the fact that $x \in D$. Consequently, for any $x \in D$ there exists a number $r=r(x) \in\left(0, r_{0}\right)$ such that $h(r)<\mu(B(x ; r))<\mu\left(\mathbb{R}^{n}\right)$. Applying a wel1 known covering theorem (see $[30], \mathrm{p} .246)$ we select a covering $\left\{\mathrm{B}\left(\mathrm{x}_{\mathrm{K}} ; \mathrm{r}_{\mathrm{K}}\right)\right\}, \mathrm{K}=1,2, \ldots$, of $\mathrm{D}$ of multiplicity $c=c(n)$ from the union of balls $\{B(x ; r(x))\}_{x \in D} \cdot$

Clearly,

$$
\sum_{K} h\left(r_{K}\right)<\sum_{K} \mu\left(B\left(x_{K} ; r_{K}\right)\right) \leq \mu\left(\mathbb{R}^{n}\right) \sum_{K} \chi\left(B\left(x_{K} ; r_{K}\right)\right) \leq c \mu\left(\mathbb{R}^{n}\right) .
$$

Thus, the lemma is proved for the case $2-\ell / n<p<n / \ell$. For the remaining values of $\mathrm{p}$, the proof is the same. Only one should use estimates (3.2)-(3.4) instead of $(3.1)$

In the following theorem, we denote by $\Phi$ a non-negative increasing function on $[0,+\infty)$, such that the function $t \Phi\left(t^{-1}\right)$ decreases and tends to zero as $t \rightarrow+\infty$. Let then for a11 $u>C$ 


$$
\int_{u}^{\infty} \psi(t) t^{-1} d t \leq a \psi(u)
$$

where

$$
\psi(v)= \begin{cases}\left(v \Phi\left(v^{-1}\right)\right)^{p^{\prime}-1}, & \text { if } 2-\ell / n \leq p<n / x, \\ \left(v \Phi\left(v^{-1}\right)\right)^{\frac{n-l}{n-p l}}, & \text { if } 1<p \leq 2-\ell / n, \\ v\left(\Phi\left(v^{1-p}\right)\right)^{p^{\prime}-1}, & \text { if } p=n / l .\end{cases}
$$

In the case $\mathrm{p}=2-\ell / \mathrm{n}$, we suppose additionally that

$$
\int_{u}^{\infty} \frac{\psi(t)}{\psi(u)}\left(\log \frac{\psi(u)}{\psi(t)}\right)^{p^{\prime}-1} \frac{d t}{t}<a .
$$

THEOREM 3.1. Let $\mathrm{p} \in(1, \mathrm{n} / \ell], \mu$ be a finite measure in $\mathbb{R}^{\mathrm{n}}$ and $\mathrm{m}$ be a positive number. Let then $\left.\mathrm{K}=\sup _{\ell, \mathrm{p}}^{\mu}(\mathrm{x}): \mathrm{x} \in \mathbb{R}^{\mathrm{n}}\right\}<+\infty$, if $1<\mathrm{p}<2-\ell / \mathrm{n}$ and $\mathrm{m}^{\mathrm{p}-1}>\mu\left(\mathbb{R}^{\mathrm{n}}\right)$, if $\mathrm{p}=\mathrm{n} / \ell$.

Then the set $G=\left\{x \in \mathbb{R}^{n}: U_{\ell, p}^{\mu}(x)>m\right\}$ can be covered by a sequence of balls $\left\{B\left(x_{K} ; r_{K}\right)\right\}$ such that

$$
\sum_{K} \Phi\left(\operatorname{cap}\left(B\left(r_{K}\right) ; S\right)\right)<a\left(b m^{1-p} \mu\left(\mathbb{R}^{n}\right)\right)
$$

where $S=h_{p}^{2}$ for $l p<n$ and $S=H_{p}^{l}$ for $l p=n$.

PROOF. Let $X$ denate a constant from (2.6), if $n>p l$ and $X=\min \left\{t: \operatorname{cap}\left(B(r) ; H_{p}^{\ell}\right\}\right.$ $\left.\leq \mathrm{t}|\log \mathrm{r}|^{1-\mathrm{p}}, \mathrm{r}<\mathrm{e}^{-1}\right\}$, if $\mathrm{n}=\mathrm{pl}$. We set in Lemma $3.1 \mathrm{~h}(\mathrm{r})=\mathrm{M}$ if $\mathrm{r}>\mathrm{r}_{\mathrm{o}}$ and

$$
h(r)=\left\{\begin{array}{l}
M \Phi\left(X_{r^{n-p l}}\right) / \Phi\left(X_{r_{0}}{ }^{n-p l}\right), \text { if } p \ell<n, r \leq r_{0}, \\
M \Phi\left(X|\log r|^{1-p}\right) / \Phi\left(X\left|\log r_{0}\right|^{1-p}\right), \text { if } p l=n, r \leq r_{0} .
\end{array}\right.
$$

The number $r_{0}$ will be chosen later to satisfy $m>a W[n]$. (W[h] was defined in Lemma 3.1)

1. Let $2-\ell / \mathrm{n}<\mathrm{p}<\mathrm{n} / \ell$. Clearly,

$$
W[h]=\int_{0}^{r}\left(\frac{h(r)}{r^{n-p l}}\right)^{p^{\prime}-1} \frac{d r}{r}+M^{p^{\prime}-1} \frac{p-1}{n-p l} r_{0}^{\frac{n-p l}{1-p}}
$$

We shall now prove that the integral at the right hand side is dominated by $\mathrm{bM}^{\mathrm{p}^{\prime}-1} \mathrm{r}_{\mathrm{o}}^{\frac{\mathrm{n}-\mathrm{p} \ell}{1-\mathrm{p}}}$. This is equivalent to the following inequality:

$$
\left(\Phi\left(\chi_{0}{ }^{n-p l}\right)\right)^{1-p^{\prime}} \int_{0}^{r}\left(\frac{\phi\left(x r^{n-p l}\right)}{r^{n-p l}}\right)^{p^{\prime}-1} \frac{d r}{r} \leq b r_{o}^{\frac{n-p l}{1-p}}
$$


Setting here $x^{-1} r^{p^{b-n}}=t$ and $x^{-1} r_{0}^{p l-n}=t_{0}$, we obtain

$$
\int_{t_{0}}^{\infty}\left(t \phi\left(t^{-1}\right)\right)^{p^{\prime}-1} \frac{d t}{t} \leq b_{1}\left(t_{o} \phi\left(t_{0}^{-1}\right)\right)^{p^{\prime}-1} \text {, }
$$

which holds by $(3.6)$. Thus

$$
\mathrm{W}[\mathrm{h}]<\mathrm{cM}^{\mathrm{P}^{\prime}-1} \mathrm{r}_{\mathrm{o}}^{\frac{\mathrm{n}-\mathrm{p} \ell}{1-\mathrm{p}}}
$$

and the inequality $a W[h]<m$ is valid provided $r_{0}{ }^{n-p l}=\left(a c m^{-1}\right)^{p-1} M$.

We introduce the set $D=\left\{x \in \mathbb{R}^{n}: U_{\ell, p}^{\mu}(x)>a W[h]\right\}$, which is open by lower semicontinuity of the $(l, p)$-potential. Since $m>a W[h]$, then $G \subset D$. Let $\left\{B\left(x_{K} ; r_{K}\right)\right\} b e$ the sequence of balls constructed for the set $D$ in Lemma 2.1 with the function $h$ chosen here. The inequality (3.5) can be rewritten as

$$
\sum_{\mathrm{K}} \phi\left(\chi_{\mathrm{K}} \mathrm{K}^{\mathrm{n}-\mathrm{pl}}\right) \leq \mathrm{a} \phi\left(\mathrm{bm} \mathrm{m}^{1-\mathrm{p}} \mathrm{M}\right)
$$

Thus, we can cover $G$ by the balls $\left\{B\left(x_{K} ; r_{K}\right)\right\}$, for which (3.8) holds.

2. If $1<p<2-\ell / n$ then the proof does not differ from the previous one.

3. Now let $\mathrm{p}=\mathrm{n} / \mathrm{l}$. Suppose that $\mathrm{r}_{\mathrm{o}}<1 / \mathrm{e}$. Here we have

$$
W[h]=\int_{0}^{r_{0}}(h(r))^{p^{\prime}-1} e^{-b r} \frac{d r}{r}+M^{p^{\prime}-1} \int_{r_{0}}^{\infty} e^{-b r} \frac{d r}{r} .
$$

The second integral can be estimated as follows

$$
\int_{r_{0}}^{\infty} e^{-b r} \frac{d r}{r}<\int_{r_{0}}^{1} \frac{d r}{r}+\int_{1}^{\infty} e^{-b r} d r \leq\left(1+b^{-1} e^{-b}\right)\left|\log r_{0}\right| .
$$

We claim that the first integral at the right hand side of (3.9) is majorized by $\mathrm{aM}^{\mathrm{P}^{\prime}-1}\left|\log \mathrm{r}_{\mathrm{o}}\right|$ or equivalent1y

$$
\left(\phi\left(x\left|\log r_{0}\right|^{1-p}\right)\right)^{1-p^{\prime}} \int_{0}^{r_{0}}\left(\phi\left(x|\log r|^{1-p}\right)\right)^{p^{\prime}-1} \frac{d r}{r}<a\left|\log r_{o}\right| .
$$

Setting here $x^{\frac{1}{1-p}}|\log r|=t$ and $x^{\frac{1}{1-p}}\left|\log r_{0}\right|=t_{0}$ we rewrite the last estimate as

$$
\int_{t_{0}}^{\infty}\left(\phi\left(t^{1-p}\right)\right)^{p^{\prime}-1} d t<a_{1} t_{0}\left(\phi\left(t_{0}^{1-p}\right)\right)^{p^{\prime}-1}
$$

which holds by (3.6). Therefore, there exists a constant $c \in(1,+\infty)$, such that

$$
\mathrm{W}[\mathrm{h}]<\mathrm{CM}^{\mathrm{P}^{\prime}-1}\left|\log \mathrm{r}_{\mathrm{O}}\right| \text {. }
$$

So the inequality aW[h] < m is satisfied, if we put

$$
\left|\log \mathrm{r}_{\mathrm{o}}\right|^{1-\mathrm{p}}=\left(\mathrm{cm}^{-1}\right)^{\mathrm{p}-1} \mathrm{M} \text {. }
$$

The rest of the proof goes as before for cases $p \in(1, n / \ell), p \neq 2-\ell / n$. 
4. We now handle the case $p=2-\ell / n$. To apply Lemma 3.1 , one must suppose $h(r) \leq e^{-1} a K^{p-1} r^{n-p l}$ for all $r \geq 0$. Since $h(r) \leq M$, the last holds if $r_{0}^{n-p l} \geq e a^{-1} k^{1-p} M$. We have

$$
\begin{aligned}
W[h]= & \int_{0}^{r_{o}}\left(\frac{h(r)}{r^{n-p l}} \log \left(a K^{p-1} \frac{r^{n-p l}}{h(r)}\right)\right)^{p^{\prime}-1} \frac{d r}{r} \\
& \quad+\int_{r_{o}}^{\infty}\left(\frac{M}{r^{n-p l}} \log \left(a K^{p-1} \frac{r^{n-p l}}{M}\right)\right)^{p^{\prime}-1} \frac{d r}{r} .
\end{aligned}
$$

The substitutions $t=a K^{p-1} M^{-1} r^{n-p l}$ and $t_{0}=a K^{p-1} M^{-1} r_{0}{ }^{n-p l}$ transform the second integral into

$$
c K \int_{t_{0}}^{\infty}(\log t / t)^{p^{\prime}-1} \frac{d t}{t}
$$

The last value is dominated by $b K\left(t_{0}{ }^{-1} \log t_{0}\right)^{p^{\prime}-1}$.

We now derive the same estimate for the first item in (3.10). It is equal to

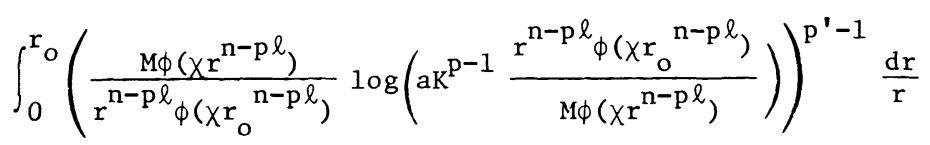

and therefore, it does not exceed $\sigma_{1}+\sigma_{2}$, where

$$
\begin{aligned}
& \sigma_{1}=c\left(\log \left(a K^{p-1} M^{-1} r_{o}^{n-p l}\right)\right)^{p^{\prime}-1} \int_{0}^{r} o\left(\frac{M \phi\left(\chi r^{n-p l}\right)}{r^{n-p l} \phi\left(\chi_{0}{ }^{n-p l}\right)}\right)^{p^{\prime-1}} \frac{d r}{r} \\
& \sigma_{2}=c \int_{0}^{r_{0}}\left(\frac{M \phi\left(\chi r^{n-p l}\right)}{r^{n-p l} \phi\left(x_{0}^{n-p l}\right)} \log \frac{r_{o}^{p l-n_{\phi}}\left(x r_{o}^{n-p l}\right)}{r^{p l-n_{\phi}\left(x r^{n-p l}\right)}}\right)^{p^{\prime-1}} \frac{d r}{r} \text {. }
\end{aligned}
$$

The inequality (3.6) implies that $\sigma_{1}<\mathrm{cK}\left(t_{0}^{-1} \log t_{0}\right)^{p^{\prime}-1}$. Setting $u=x^{-1} r^{p l-n}$, $u_{o}=x^{-1} r_{0}^{p l-n}$ and using the condition (3.7), we get

$$
\sigma_{2}=\operatorname{cM}^{p^{\prime}-1} u_{0}^{p^{\prime}-1} \int_{u_{0}}^{\infty} \frac{\psi(u)}{\psi\left(u_{0}\right)}\left(\log \frac{\psi\left(u_{o}\right)}{\psi(u)}\right)^{p^{\prime}-1} \frac{d u}{u} \leq c k\left(t_{0}^{-1} \log t_{o}\right)^{p^{\prime}-1} .
$$

Thus, $W[h] \leq c K\left(\log t_{o} / t_{0}\right)^{p^{\prime}-1}$ where $t_{0}=a K^{p-1} M^{-1} r_{o}{ }^{n-p l}>$ e. Let $\theta$ denote the inverse to the function $t \rightarrow c K\left(t^{-1} \log t\right)^{p^{\prime}-1}(t>e)$. Then the inequality aW[h]<m

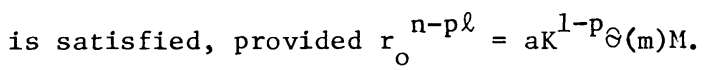

It remains now to repeat the same argument as in the first part of the proof. Thus, the proof of the theorem is complete.

NOTE 3.1. It follows from the proof of Theorem 3.1 that in case $\mathrm{pl}=\mathrm{n}$, the radii of balls, covering the set $G$, can be chosen less than $\mathrm{e}^{-1}$.

COROLLARY 3.1. Let $1<\mathrm{p} \leq \mathrm{n} / \ell$ and $\Phi$ be the function defined before Theorem 3.1 . 
Let then $E \subset \mathbf{R}^{\mathrm{n}}$ be a Borel set, such that $\operatorname{cap}(\mathrm{E} ; \mathrm{S})>0$, where $\mathrm{S}=\mathrm{h}_{\mathrm{p}}^{\ell}$, if $\mathrm{pl}<\mathrm{n}$ and $\mathrm{S}=\mathrm{H}_{\mathrm{p}}^{\ell}$, if $\mathrm{p} l=\mathrm{n}$. Then there exists a covering of $\mathrm{E}$ by balls $\mathrm{B}\left(\mathrm{x}_{\mathrm{K}} ; \mathrm{r}_{\mathrm{K}}\right)$ such that

$$
\sum_{\mathrm{K}} \phi\left(\operatorname{cap}\left(B\left(\mathrm{r}_{\mathrm{K}}\right) ; \mathrm{S}\right)\right)<\mathrm{C} \phi(\mathrm{C} \operatorname{cap}(\mathrm{E} ; \mathrm{S}))
$$

with constant $\mathrm{C}$ depending on $\mathrm{n}, \mathrm{p}, l$ and the function $\phi$. In case $\mathrm{p} l=\mathrm{n}$, one can choose $r_{K} \leq e^{-1}$.

PROOF. We limit consideration to the case $\mathrm{p} l<\mathrm{n}$. If $\mathrm{pl}=\mathrm{n}$, the arguments are the same. We denote by $\mu$ the $(l, p)$-capacitary measure of $E$ and put $G_{\varepsilon}=\left\{x \in \mathbb{R}^{n}: U_{\ell, p}^{\mu}(x)>1-\varepsilon\right\}, \varepsilon>0$. Since

$$
\mathrm{U}_{\ell, \mathrm{p}}^{\mu}(\mathrm{x}) \geq 1 \quad(\ell, \mathrm{p})-\mathrm{q} \cdot \mathrm{e} \text {. on } \mathrm{E},
$$

then $E=G_{\varepsilon} \cup E_{O}$, where $\operatorname{cap}\left(E_{o} ; h_{p}^{l}\right)=0$.

By Theorem 3.1 there exists a covering of $G_{\varepsilon}$ by balls $B\left(x_{j} ; r_{j}\right)$, such that (3.8) holds with $\mathrm{m}=1-\varepsilon$ and $\mu\left(\mathbb{R}^{\mathrm{n}}\right)=\operatorname{cap}\left(\mathrm{E} ; \mathrm{h}_{\mathrm{p}}^{l}\right)$.

Since the function $\psi(t) / t$ is summable on $[1,+\infty)$, then the function $h$ defined as $h(r)=\phi\left(\operatorname{cap}\left(B(r) ; h_{p}^{l}\right)\right)$ satisfies the condition (2.8). Hence by Proposition 2.4 it follows that $E_{O}$ has a zero Hausdorff h-measure. Therefore, one can cover $E_{O}$ by balls $B\left(y_{i} ; \rho_{i}\right)$ so that the inequality

holds.

$$
\sum_{i} \phi\left(\operatorname{cap}\left(B\left(\rho_{i}\right) ; h_{p}^{l}\right)\right)<\varepsilon
$$

The union of balls $B\left(x_{j} ; r_{j}\right)$ and $B\left(y_{i} ; \rho_{i}\right)$ gives the required covering.

COROLLARY 3.2. Let $\mathrm{p} \in(1, \mathrm{n} / \mathrm{l}], \mathrm{s}=\mathrm{h}_{\mathrm{p}}^{2}$, if $\mathrm{p} \ell<\mathrm{n}$ and $\mathrm{s}=\mathrm{H}_{\mathrm{p}}^{\ell}$, if $\mathrm{p} \ell=\mathrm{n}$. Let $\Phi$ be the function defined before Theorem 3.1. If measure $\mu$ is such that for any ball $B(x ; \rho)$

$$
\mu(B(x ; \rho)) \leq \phi(a \operatorname{cap}(B(\rho) ; S)),
$$

then for any Borel set $E$ with finite capacity cap $(E ; S)$ the inequality holds

$$
\mu(E) \leq C \Phi(C \operatorname{cap}(E ; 3)) .
$$

Here $C$ is a constant, depending on $n, p, l$ and on function $\Phi$.

PROOF. Let $E \subset \mathbb{R}^{n}$ and $\operatorname{cap}(E ; S)<\infty$. Then according to the Corollary 3.1, E can be covered by balls $B\left(x_{K} ; r_{K}\right)$, satisfying (3.11). Using the additivity of the measure $\mu$, as well as condition (3.12), we obtain 


$$
\begin{aligned}
\mu(E) & \leq \mu\left(\bigcup_{K} B\left(x_{k} ; r_{K}\right)\right) \leq \sum_{K} \mu\left(B\left(x_{K} ; r_{K}\right)\right) \\
& \leq \sum_{K} \Phi\left(a \operatorname{cap}\left(B\left(r_{K}\right) ; S\right)\right)<C \Phi(C \operatorname{cap}(E ; S)),
\end{aligned}
$$

which completes the proof of the corollary.

NOTE 3.2. According to $(2.4), \operatorname{cap}\left(E ; H_{p}^{l}\right) \sim \operatorname{cap}\left(E ; h_{p}^{l}\right)$ if $\operatorname{diamE} \leq 1$. So under the additional condition $\operatorname{diamE} \leq 1$, we can take $\mathrm{S}=\mathrm{H}_{\mathrm{p}}^{\ell}$ also if $\mathrm{p} \ell<\mathrm{n}$ in Corollary 3.2 .

To show this we verify that the measure $\mathbb{R}^{n} \supset A \rightarrow \mu_{1}(A)=\mu(A \cap E)$ satisfies the condition (3.12).

Suppose diamE $\leq 1$ and let the inequality

$$
\mu(B(x ; r)) \leq \phi\left(\operatorname{cap}\left(B(r) ; H_{p}^{l}\right)\right)
$$

hold for all $r \in(0,1)$. For $r<1$, we have

$$
\begin{aligned}
\mu_{1}(B(x ; r)) & =\mu(B(x ; r) \cap E) \leq \mu(B(x ; r)) \\
& \leq \phi\left(\operatorname{cap}\left(B(r) ; H_{p}^{l}\right)\right) \leq \phi\left(a \operatorname{cap}\left(B(r) ; h_{p}^{l}\right) .\right.
\end{aligned}
$$

If $r \geq 1$ then for any $y \in E$

$$
\mu_{1}(B(x ; r)) \leq \mu(B(y ; 1)) .
$$

Hence, using (3.13) and the monotony of capacity, we obtain

$$
\mu_{1}(B(x ; r)) \leq \Phi\left(\operatorname{cap}\left(B(1) ; H_{p}^{l}\right)\right) \leq \Phi\left(a \operatorname{cap}\left(B(r) ; h_{p}^{l}\right)\right) .
$$

So the measure $\mu_{1}$ satisfies the condition (3.12).

4. APPLICATIONS TO EMBEDDING THEOREMS.

In this section we present embedding theorems of potential spaces into some spaces of functions summable with respect to arbitrary measure in $\mathbb{R}^{\mathrm{n}}$.

We use the following known fact mentioned in section 1 .

PROPOSITION 4.1. Let $0<\ell<\mathrm{n}$ and $\mathrm{l}<\mathrm{p} \leq \mathrm{n} / \ell$. Then for any function $\mathrm{u} \in \mathrm{C}_{\mathrm{O}}^{\infty}$ the inequality (1.4) holds with $\mathrm{S}=\mathrm{H}_{\mathrm{p}}^{\ell}$, if $\mathrm{p} \ell \leq \mathrm{n}$ and $\mathrm{s}=\mathrm{h}_{\mathrm{p}}^{\ell}$, if $\mathrm{p} \ell<\mathrm{n}$.

PROOF. We limit consideration to the space $H_{p}^{l}$, since the arguments are the same for the space $h_{p}^{l}$. It is sufficient to take $u=J_{\ell} f, f \geq 0, f \in L^{p}$. Let $\mu_{t}$ be the capacitary measure of the set $Q_{t}$. The left hand side of (1.4) does not exceed the value

$$
\int_{0}^{\infty} \int J_{\ell} f d \mu_{t} t^{p-2} d t=\int f d x \int_{0}^{\infty} J_{\ell} \mu_{t} t^{p-2} d t,
$$

which is dominated by 


$$
\|f\| \cdot\left\|\int_{0}^{\infty} t^{p-2} J_{\ell} \mu_{t} d t\right\|_{p} \cdot
$$

Therefore, the theorem follows if the inequality

$$
\int\left(\int_{0}^{\infty} t^{\mathrm{p}-2} J_{\ell^{\mu}} \mathrm{dt}^{\mathrm{p}}\right)^{\mathrm{p}^{\prime}} \mathrm{dx} \leq \mathrm{A}_{\mathrm{p}}^{\mathrm{p}^{\prime}-1} \int_{0}^{\infty} \operatorname{cap}\left(\mathrm{Q}_{\mathrm{t}} ; \mathrm{H}_{\mathrm{p}}^{\ell}\right) \mathrm{t}^{\mathrm{p}-1} \mathrm{dt}
$$

is proved. We note at first that by the maximum principle

$$
\int J_{\ell} \mu_{t}\left(J_{\ell} \mu_{\tau}\right)^{p^{\prime}-1} d x \leq M \operatorname{cap}\left(Q_{t} ; H_{p}^{\ell}\right) .
$$

Consider then the cases $p \geq 2$ and $p<2$ separately. Let $p \geq 2$. We rewrite the left hand side of (4.1) as

$$
p^{\prime} \iint_{0}^{\infty} J_{\ell} \mu_{\tau}\left(\int_{\tau}^{\infty} J_{\ell} \mu_{t} t^{p-2} d t\right)^{p^{\prime}-1} \tau^{p-1} d \tau d x .
$$

By the Hölder inequality, this value has the upper bound

$$
\mathrm{p}^{\prime}\left(\iint_{0}^{\infty} \tau^{\mathrm{p}-1}\left(\mathrm{~J}_{\ell} \mu_{\tau}\right)^{\mathrm{p}^{\prime}} \mathrm{d \tau} \mathrm{dx}\right)^{\ell-\mathrm{p}^{\prime}}\left(\iint_{0}^{\infty}\left(\mathrm{J}_{\ell} \mu_{\tau}\right)^{\mathrm{p}^{\prime}-1} \int_{\tau}^{\infty} \mathrm{J}_{\ell} \mu_{t} \mathrm{t}^{\mathrm{p}-2} \mathrm{dt} \mathrm{d} \tau \mathrm{dx}\right)^{\mathrm{p}^{\prime}-1}
$$

which does not exceed

$$
\mathrm{P}^{\prime} \mathrm{M}^{\mathrm{p}^{\prime}-1}\left(\int_{0}^{\infty}\left\|J_{\ell^{\mu}}\right\|_{\mathrm{p}^{\prime}}^{\mathrm{p}^{\prime}} \mathrm{t}^{\mathrm{p}-1} \mathrm{dt}\right)^{2-\mathrm{p}^{\prime}}\left(\int_{0}^{\infty} \operatorname{cap}\left(\mathrm{Q}_{\mathrm{t}} ; \mathrm{H}_{\mathrm{p}}^{\ell}\right) \mathrm{t}^{\mathrm{p}-1} \mathrm{dt}\right)^{\mathrm{p}^{\prime}-1}
$$

by (4.2). So the inequality $(4.1)$ is proved for $p \geq 2$.

Now let $p<2$. The left hand side of (4.1) is equal to

$$
\mathrm{p}^{\prime} \iint_{0}^{\infty} \mathrm{J}_{\ell} \mu_{\tau} \mathrm{t}^{\mathrm{p}-2} \mathrm{dt}\left(\int_{0}^{\mathrm{t}} \mathrm{J}_{\ell} \mu_{\tau} \tau^{\mathrm{p}-2} \mathrm{~d} \tau\right)^{\mathrm{p}^{\prime}-1} \mathrm{dx}
$$

and so, according to the Minkowski inequality, is not less than

$$
\mathrm{p}^{\prime} \int_{0}^{\infty}\left(\int_{0}^{\mathrm{t}}\left(\int\left(\mathrm{J}_{\ell^{\mu}} \tau\right)^{\mathrm{p}^{\prime}-1} \mathrm{~J}_{\ell^{\mu}}{ }_{t} \mathrm{dx}\right)^{\mathrm{p}-1}{ }^{\mathrm{p}-2} \mathrm{~d} \tau\right)^{\mathrm{p}^{\prime}-1}{ }_{\mathrm{t}^{\mathrm{p}-2} \mathrm{dt} .}
$$

Using (4.2), we obtain the following majorant for this value

$$
\mathrm{p}^{\prime} \mathrm{M} \int_{0}^{\infty} \operatorname{cap}\left(\mathrm{Q}_{\mathrm{t}} ; \mathrm{H}_{\mathrm{p}}^{\ell}\right)\left(\int_{0}^{\mathrm{t}} \tau^{\mathrm{p}-2} \mathrm{~d} \tau\right)^{\mathrm{p}^{\prime}-1} \mathrm{t}^{\mathrm{p}-2} \mathrm{dt} .
$$

Thus, (4.1) is proved for $\mathrm{p}<2$.

THEOREM 4.1. (cf. [5]). The exact constant $A$ in the inequality

$$
\left\||\mathrm{u}|^{\mathrm{P}} ; \mathrm{L}_{\mathrm{M}}(\mu)\right\| \leq \mathrm{A}\|\mathrm{u} ; \mathrm{S}\|,
$$

where $S=h_{p}^{l}$, if $p \ell<n$ and $S=H_{p}^{l}$, if $p l \leq n$, is equivalent to the value

$$
B=\sup \left\{\frac{\mu(E) N^{-1}(1 / \mu(E))}{\operatorname{cap}(E ; S)}: E \subset \mathbb{R}^{n}, \operatorname{cap}(E ; S)>0\right\} .
$$


PROOF. From the definition of the norm in $L_{11}(\mu)$ and the equality (2.10), we obtain

$$
\begin{aligned}
& \left\||u|^{p} ; L_{M}(\mu)\right\|=\sup \left\{p \int_{0}^{\infty} \int_{Q_{\tau}} v d \mu \tau^{p-1} d \tau: \int N(v) d \mu \leq 1\right\} \\
& \leq \mathrm{p} \int_{0}^{\infty} \sup \left\{\int X_{\tau} \mathrm{vd} \mu: \int \mathrm{N}(\mathrm{v}) \mathrm{d} \mu \leq 1\right\} \tau^{\mathrm{p}-1} \mathrm{~d} \tau \\
& =p \int_{0}^{\infty}\left\|x_{\tau} ; L_{M}(\mu)\right\| \tau^{p-1} d \tau=p \int \mu\left(Q_{\tau}\right) N^{-1}\left(1 / \mu\left(Q_{\tau}\right)\right) \tau^{p-1} d \tau
\end{aligned}
$$

(Here $X_{\tau}$ is the characteristic function of the set $Q_{\tau}=\{x:|u(x)| \geq \tau\}$ ). This and (4.4) lead to the estimate

$$
\left\||u|^{p} ; L_{\mathcal{H}}(\mu)\right\| \leq p B \int_{0}^{\infty} \operatorname{cap}\left(Q_{\tau} ; S\right) \tau^{p-1} d \tau \leq \operatorname{cpB}\|u ; S\|^{p},
$$

where $c$ is a constant from (1.4). Thus $A \leq \mathrm{cpB}$.

We now derive the opposite estimate. Let $K$ denote an arbitrary compact in $\mathbb{R}^{n}$ and $u$ be any function from $C_{0}^{\infty}$ such that $u \geq 1$ on $k$. Putting $u$ into (4.3) and using the definition of the $(\ell, p)$-capacity, we obtain

$$
\mu(\mathrm{K}) \mathrm{N}^{-1}(1 / \mu(\mathrm{K})) \leq \mathrm{A} \operatorname{cap}(\mathrm{K} ; \mathrm{S}) \text {. }
$$

The passage from compacts to any Borel sets can be performed in a standard way. So $\mathrm{B} \leq \mathrm{A}$. The proof of the theorem is complete.

THEOREM 4.2. Let $M$ be a convex function satisfying the conditions formulated in 2.3, and $\mathrm{N}$ be a complementary function to $\mathrm{M}$. Let then $\Phi$ be the inverse function to $t \rightarrow t N^{-1}(1 / t)$, subjected to condftion (3.6), and in addition to condition (3.7), if $\mathrm{p}=2-\ell / \mathrm{n}$. Then $(\alpha)$ the exact constant $\mathrm{A}$ in the inequality (4.3) with $\mathrm{s}=\mathrm{h}_{\mathrm{p}}^{\ell}$, $l_{\mathrm{p}}<\mathrm{n}$, is equivalent to

$$
\mathrm{C}_{1}=\sup \left\{\rho^{\ell \mathrm{p}-\mathrm{n}} \mu(\mathrm{B}(\mathrm{x} ; \rho)) \mathrm{N}^{-1}(1 / \mu(\mathrm{B}(\mathrm{x} ; \rho))): \mathrm{x} \in \mathbb{R}^{\mathrm{n}} ; \rho>0\right\} .
$$

$(\beta)$ the exact constant $A$ in (4.3) with $S=H_{p}^{l}$ is equivalent to

$$
C_{2}=\sup \left\{\rho^{\ell p-n} \mu(B(x ; \rho)) N^{-1}(1 / \mu(B(x ; \rho))): x \in \mathbb{I R}^{n} ; 0<\rho<1\right\},
$$

if $\mathrm{p} \ell<\mathrm{n}$ and to

$$
C_{3}=\sup \left\{|\log \rho|^{P^{-1}} \mu(B(x ; \rho)) N^{-1}(1 / \mu(B(x ; \rho))): x \in \mathbb{R}^{n} ; 0<\rho<1 / 2\right\} \text {, }
$$

if $\mathrm{p} \ell=\mathrm{n}$.

The proof follows immediately from Theorem 4.1 and the equivalence $B \sim C_{j}$, $j=1,2,3$ obtained in Corollary 3.2 and Note 3.2 . 
NOTE 4.1. The constant $A$ in (4.3) with $S=H_{p}^{l}$, $p l>n$, is equivalent to

$$
C_{4}=\sup \left\{\mu(B(x ; 1)) N^{-1}\left(1 / \mu(B(x ; 1)): x \in \mathbb{R}^{n}\right\} .\right.
$$

Indeed, let $\left\{\eta^{(j)}\right\}$ be a partition of unity subordinate to a covering of $\mathbb{R}^{\mathrm{n}}$ by unit balls $\left\{\mathrm{B}^{(j)}\right\}$ with finite multiplicity. From the definition of the norm in $\mathrm{L}_{11}(\mu)$ and Sobolev's Theorem on embedding $H_{p}^{l}$ into $L^{\infty}\left(\mathbb{R}^{n}\right)$ we obtain

$$
\begin{aligned}
\left\||u|^{p} ; L_{M}(\mu)\right\| & \leq c \sum_{j}\left\|\left|u{ }^{(j)}\right|^{P} ; L_{M}(\mu)\right\| \\
& \leq c_{1} \sum_{j}|| \chi\left(\cdot ; B^{(j)}\right) ; L_{M}(\mu)\|\cdot\| u \eta^{(j)} ; H_{p}^{\ell}||^{p} \\
& \leq c_{1} C_{4} \sum_{j}|| u n{ }^{(j)} ; H_{p}^{\ell} \|^{p} .
\end{aligned}
$$

The last sum does not exceed $c|| u ; H_{p}^{l} \|^{P}$ (see [31]), hence $A \leq c_{2} C_{4}$. The opposite estimate follows from (4.3) by substituting the function $\eta \in C_{0}(B(x ; 2)), \eta=1$ on $\mathrm{B}(\mathrm{x} ; 1)$.

Now D.R. Adam's theorem, mentioned in our Introduction, follows from $(\alpha)$ of Theorem 4.2 with $M(t)=t^{q / p}, q>p$.

NOTE 4.2. (see [32]). If $q=p$, then the condition (1.5) is not sufficient for (1.2) to hold. Let $q=p, n>p l$. We choose a Borel set $E$ with a finite and positive ( $n$ - pl)-dimensional Hausdorff measure. We can take $E$ to be closed and bounded (since any Borel set of positive Hausdorff measure contains a bounded subset with the same property). According to Frostman's theorem (see [33], Theorem 1, Chapter II) there exists a measure $\mu$ with support in $E$, such that

$$
\mu(B(x ; \rho)) \leq c \rho^{n-p \ell}
$$

where $c$ is a constant, independent of $x$ and $\rho$. By Proposition 2.3, $\operatorname{cap}\left(E ; H_{p}^{l}\right)=0$. On the other hand, from (1.2) it follows that $\mu(E) \leq A \operatorname{cap}\left(E ; H_{p}^{l}\right)$ and hence $\mu(E)=0$.

This contradiction shows that (1.2) fails although (4.5) holds.

Setting $M(t)=t^{q / p}$ in Theorem 4.2, we obtain the following new result for the case $\ell_{\mathrm{p}}=\mathrm{n}$.

COROLLARY 4.1. If $\ell p=n$, then the exact constant $A$ in

$$
|| \mathrm{u} ; \mathrm{L}^{\mathrm{q}}(\mu) \| \leq \mathrm{A}|| \mathrm{u} ; \mathrm{H}_{\mathrm{p}}^{\ell}||
$$

is equivalent to 


$$
C_{5}=\sup \left\{|\log \rho|^{p-1}[\mu(B(x ; \rho))]^{p / q}: x \in \mathbb{R}^{n} ; 0<\rho<1 / 2\right\} .
$$

The following statement, obtained in [13] by another method and relating to the case $\mathrm{p} \ell=\mathrm{n}$ and measures of positive dimension, follows easily from Theorem 4.2.

COROLLARY 4.2. Let $\mathrm{p} l=\mathrm{n}$ and $\mathrm{M}(\mathrm{t})=\exp \left(\mathrm{t}^{\mathrm{p}^{\prime}-1}\right)-1$. The inequality $(4.3)$ holds if and only if for some $\beta>0$ :

$$
\sup \left\{\rho^{-\beta} \mu(B(x ; \rho)): \quad x \in \mathbb{R}^{n} ; 0<\rho<1\right\}<\infty .
$$

PROOF. Since $N^{\prime}(t)=(\log t)^{p-1}(1+o(1))$ as $t \rightarrow \infty$ then $\Phi^{-1}(t)=t^{-1}(1 / t)=$ $(\log t)^{1-p}(1+o(1))$. Hence, $\log \Phi(t)=-t^{p^{\prime}-1}(1+o(1))$. Obviously, $\Phi$ satisfies the condition (3.6). It remains now to use $\operatorname{cap}\left(B(\rho) ; H_{p}^{l}\right) \sim|\log \rho|^{1-p}$ with $\rho \in(0 ; 1 / 2)$ and to apply Theorem 4.1. The proof is complete.

NOTE 4.3. Since $\mathrm{B}_{\mathrm{p}}^{\ell}\left(\mathrm{IR}^{\mathrm{n}}\right)$ is the space of traces on $\mathbf{R}^{\mathrm{n}}$ of functions from $H_{p}^{l+1 / p}\left(\mathbb{R}^{n+1}\right)([17])$ then Theorem 4.2 and Corollary 4.1 still hold if $\operatorname{space}^{\ell}\left(\mathbb{I R}^{n}\right)$ is changed to $B_{p}^{\hat{\imath}}\left(\mathbb{R}^{n}\right)$.

\section{REFERENCES}

1. SOBOLEV, S.L. On a theorem of functional analysis, Matem. Sbornik 46:3 (1938), 471-497.

2. IL'IN, V.P. An imbedding theorem for the limit exponent, Dokl. Akad. Nauk SSSR 96 (1954), 905-908.

3. MAZ'JA, V.G. On some integral inequalities for functions of several variables, Problemy Matem. Analyza 3 , Leningrad University (1972), 33-68.

4. MAZ'JA, V.G. On negative spectrum of multidimensional Schrödinger operator, Dokl. Akad. Nauk SSSR 144:4 (1962), 721-722.

5. MAZ'JA, V.G. On the theory of multidimensional Schrödinger operator, Izvestia Akad. Nauk SSSR, Ser. Matem. 28:5 (1964), 1145-1172.

6. ADAMS, D.R. On the existence of capacitary strong estimates in $\mathbb{R}^{n}$, Ark. Mat. $14: 1$ (1976), 125-140.

7. MAZ'JA, V.G. On capacitary strong type estimates for "fractional" norms, Zap. Naucn. Sem. Leningrad Otdel. Inst. Steklov (LOMI) 70 (1977), 161-168.

8. DAHLBERG, B.E.T. Regularity properties of Riesz potentials, Indiana Univ. Math. Journal 28:2 (1979), 257-268.

9. HEDBERG, L.I. On certain convolution inequalities, Proc. Amer. Math. Soc. $\underline{36: 2}$ (1972), 505-510.

10. LIZORKIN, P.I. Boundary properties of functions from "Weighted classes", Dok1. Akad. Nauk SSSR 132 (1960), 514-517.

11. USPENSKII , S.V. Imbedding theorems for weighted classes, Trudy Mat. Inst. Steklov $60(1961), 282-303$. 
12. HANSSON, K. Imbedding theorems of Sobolev type in potential theory, Math. Scand. 45 (1979), 77-102.

13. ADAMS, D.R. Traces of potentials II, Indiana Univ. Math. J. 22:10 (1973), 907-918.

14. ADAMS, D.R. A trace inequality for generalized potentials, Studia Math. 48:1 (1973), 99-105.

15. MAZ'JA, V.G. On summability with respect to an arbitrary measure of functions from Sobolev-Slobodetsky spaces, Zap. Naucn, Sem. Leningrad. Otdel. Mat. Inst. Steklov (LOIII) 92 (1979), 192-202.

16. ADAMS, D.R. and MEYERS, N.G. Thinness and Wiener criteria for nonlinear potentials, Indiana Univ. Math. J. 22:2 (1972), 139-158.

17. STEIN, E.M. Singular Integrals and Differentiability Properties of Functions, Princeton Univ. Press (1970).

18. IAZ'JA, V.G. and HAVIN, V.P. Non-linear potential theory, Us pehi Mat. Nauk. 27:6 (1972), 67-138.

19. MEYERS, N.G. A theory of capacities for potentials of functions in Lebesgue classes, Math. Scand. 26:2 (1970), 255-292.

20. MAZ'JA, V.G. Classes of sets and measures connected with imbedding theorems in "Imbedding Theorems and their Applications", Proc. Symp. on Imbedding Theorems, Baku, 1966, Nauka, Moscow (1970), 142-159.

21. MAZ'JA, V.G. On the removable singularities of bounded solutions of quasilinear elliptic equations of arbitrary order, Zap. Naucn. Sem. Leningrad. Otdel. Mat. Inst. Steklov (LOMI) 27 (1972), 116-130.

22. ADAMS, D.R. and POLKING, T.C. The equivalence of two definitions of capacity, Proc. Amer. Math. Soc. 37:2 (1973), 529-534.

23. ADAMS, D.R. and MEYERS, N.G. Bessel potentials: Inclusion relations among classes of exceptional sets, Indiana Univ. Math. J. 22:9 (1973), 873-905.

24. SJÖDIN, T. Capacities of compact sets in linear subspaces of $\mathbb{R}^{n}$, Pacific J. Math. 78:1 (1978), 261-266.

25. ADAMS, D.R. On the exceptional sets for spaces of potentials, Pacific J. Math. $\underline{52: 1}(1974), 1-5$.

26. MAZ'JA, V.G. and HAVIN, V.P. Nonlinear analog of the Newtonian potential and metric properties of the ( $p, \ell)$-capacity, Dokl. Akad. Nauk SSSR 194 (1970), 770-773.

27. KRASNOSEL'SKII, M.A. and RUTITSKII, Ya.B. Convex functions and Orlicz spaces, Moscow, Fismatgiz (1958).

28. CARTAN, H. Sur les systemes des fonctions holomorphes à variétés linéaires et leurs applications, Thèse de Paris, (1928).

29. NEVANLINNA, R. Eindeutige analytische Funktionen, 1953.

30. LANDKOF, N.S. Foundations of Modern Potential Theory, "Nauka", Moscow (1966).

31. STRIChARTZ, R.S. Multipliers on fractional Sobolev spaces, J. Math. and Mech. $16: 9$ (1967), 1031-1060. 
32. ADAMS, D.R. Traces of potentials arising from translation invariant operators, Ann. Sc. Norm. Pisa 25:1 (1971), 203-217.

33. CARLESON, L. Selected problems on exceptional sets, Van Nostrand, Princeton, NJ, (1967).

34. MAZ'JA, V.G. An imbedding theorem and multipliers in pairs of Sobolev spaces, Trudy Matem. Inst. Akad. Nauk Gruz. SSSR 66 (1980), 59-69.

35. FEDERER, H. and FLEMING, W.H. Normal and integral currents, Ann. of Math. 72 $(1960), 458-520$.

36. MAZ'JA, V.G. Classes of domains and imbedding theorems for functional spaces, Dok1. Akad. Nauk SSSR 133: 3 (1960), 527-530.

37. BURAGO, Yu.D. and MAZ'JA, V.G. Potential theory and function theory for irregular regions, Zapiski Naucn. Sem. (LOMI) 3 (1967). Engl1sh translated by Consultants Bureau, 1969.

38. MEYERS, N.G. and ZIEMER, W.P. Integral inequalities of Poincaré and Wirtinger type for BV functions, Amer. J. Math. 99 (1977), 1345-1360.

39. MAZ'JA, W. Einbettungssätze für Sobolesche Räume, Teil 1 (1979), Teil 2 (1980), Teubner-Texte, zur. Mathematik, Leipzig.

40. MAZ'JA, W. Zur Theorie Sobolevscher Räume, Teubner-Texte, zur Mathematik, Leipzig (1981). 


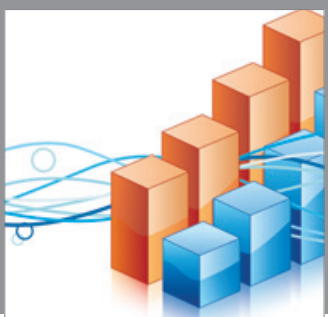

Advances in

Operations Research

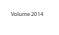

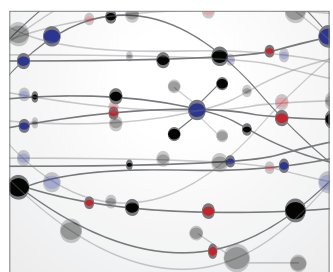

\section{The Scientific} World Journal
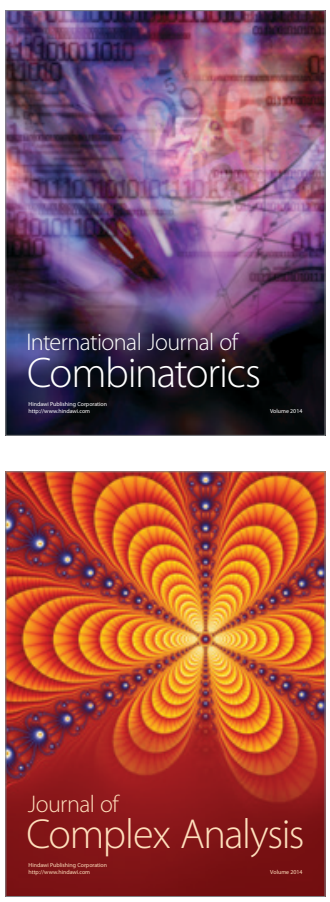

International Journal of

Mathematics and

Mathematical

Sciences
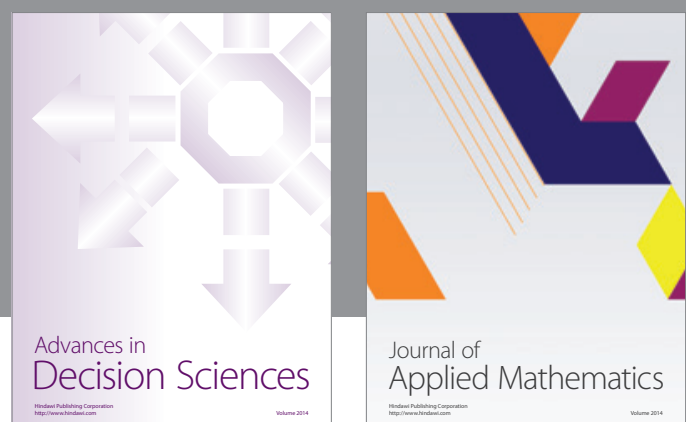

Journal of

Applied Mathematics
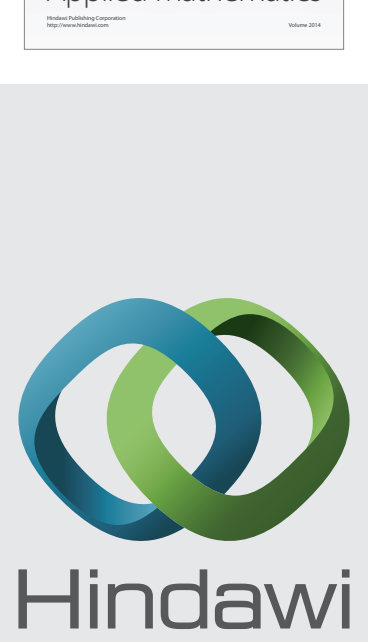

Submit your manuscripts at http://www.hindawi.com
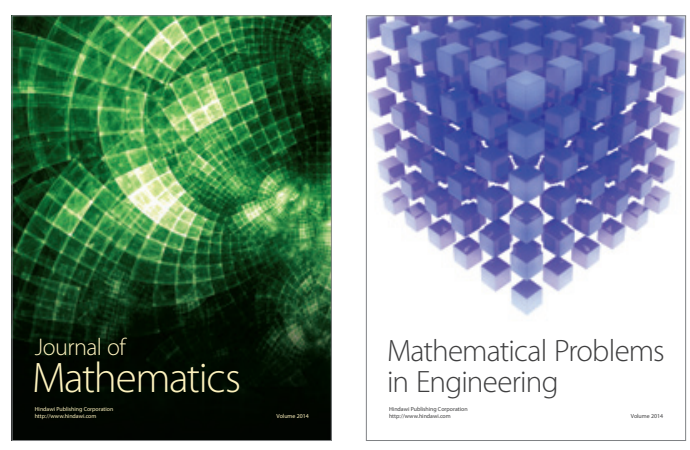

Mathematical Problems in Engineering
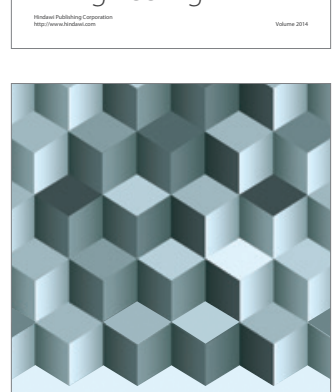

Journal of

Function Spaces
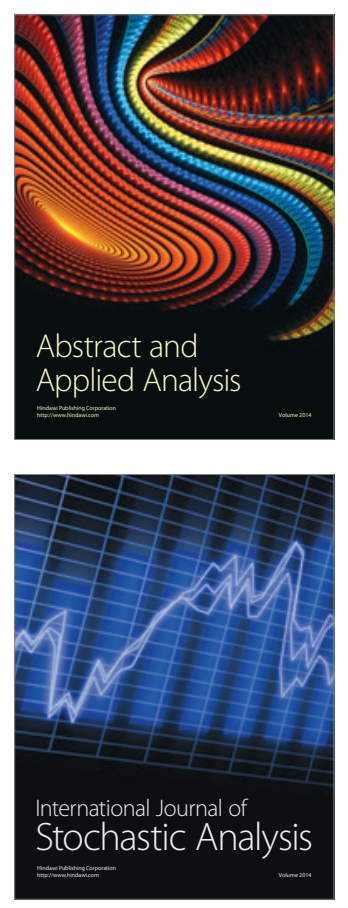

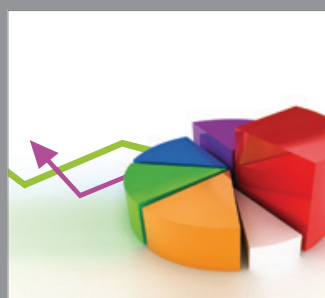

ournal of

Probability and Statistics

Promensencen
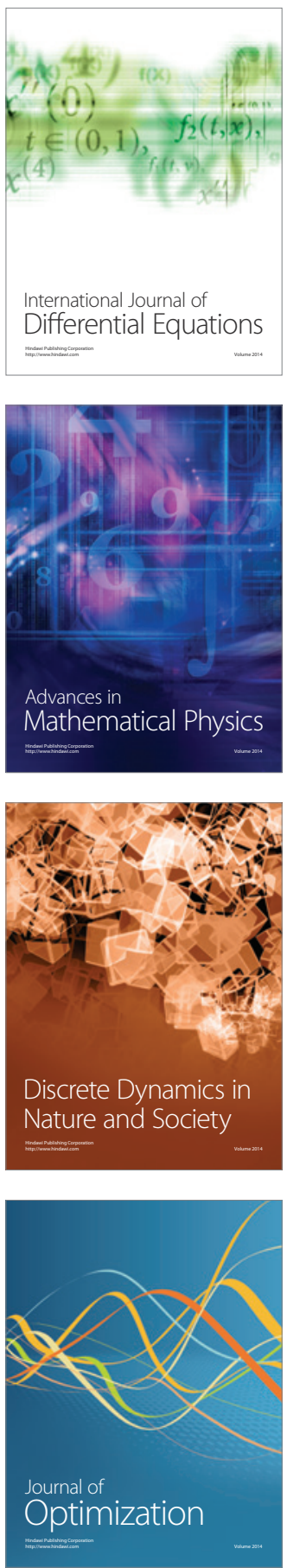